\title{
Concentrations of pyridinoline and deoxypyridinoline in joint tissues from patients with osteoarthritis or rheumatoid arthritis
}

\author{
Masaaki Takahashi, Kazuhiro Kushida, Hironobu Hoshino, Motohiro Suzuki, \\ Michio Sano, Shigehito Miyamoto, Tetsuo Inoue
}

\begin{abstract}
Objective-To assess the usefulness of pyridinoline (Pyr) and deoxypyridinoline (Dpyr), intermolecular crosslinks of collagen, as markers in the evaluation of arthritis, by studying their distribution in tissues from knee joints.

Methods-Joint tissues (cartilage, bone, synovium) were obtained during operation from 10 patients with osteoarthritis (OA) and 10 patients with rheumatoid arthritis (RA). Synovium was also obtained from 10 non-arthritic (NA) subjects. Hydroxyproline was measured in hydrolysed tissue samples and converted to an equivalent collagen content. The amounts of Pyr and Dpyr crosslinks measured in the hydrolysed samples using a fluorescence technique were expressed as $\mu \mathrm{mol} / \mathrm{mol}$ of collagen.
\end{abstract}

Results-Pyr and Dpyr were distributed in all three tissues, but in different amounts. The ratio of the contents of Pyr and (Pyr:Dpyr) was 50:1 in cartilage, 3:1 in bone, and $25: 1$ in synovium. $O A$ cartilage had a greater Dpyr content than the RA cartilage, but there was no other significant difference in the contents of Pyr and Dpyr and the ratio Pyr:Dpyr in the joint tissues from patients with $O A$ or RA. In synovium, there was no significant difference between the contents of Pyr and Dpyr and the Pyr:Dpyr ratio among $O A$, RA, and NA tissues.

Conclusion-Both Pyr and Dpyr were located in cartilage, bone, and synovium. A significant amount of Pyr and Dpyr in these joint tissues, especially in synovium, may contribute to the urinary excretion of those crosslinks that is observed in arthritis.

(Ann Rheum Dis 1996; 55: 324-327)

Pyridinoline (Pyr), ${ }^{12}$ and its analogue, deoxypyridinoline (Dpyr), ${ }^{3}$ are non-reducible crosslinks of mature collagen. The distribution of the pyridinium crosslinks was reported a decade ago: Pyr is distributed in most collagenous tissues, primarily in cartilage and bone, ${ }^{4}$ while significant amounts of Dpyr were reported to be distributed only in bone and dentin. However, as Dpyr has subsequently been detected in cardiovascular muscle, aorta, and cartilage in disease states, ${ }^{5}{ }^{6}$ its distribution is evidently not restricted to bone and dentin. The tissue distribution of pyridinium crosslinks thus requires reassessment.

The urinary concentrations of Pyr and Dpyr have been used as markers of bone metabolism, especially bone resorption, and many observers have reported the usefulness of these urinary Pyr and Dpyr values in the assessment of various metabolic bone diseases. ${ }^{7}$ In contrast, as the tissue distribution of $\mathrm{Pyr}$ favours cartilage, in addition to its presence in bone, urinary Pyr content may serve as a marker of cartilage metabolism. High urinary excretion of Pyr has been observed in a preliminary analysis in osteoarthritis $(\mathrm{OA})^{8}$ and in rheumatoid arthritis (RA), ${ }^{9}$ and several observers have proposed that urinary pyridinium crosslinks could be markers of arthritis. ${ }^{10-15}$ However, relationships between the distribution of pyridinium crosslinks in the joint tissues, the origin of urinary Pyr or Dpyr crosslinks, and the significance of the urinary excretion of the crosslinks as biochemical markers in arthritis, have not been established. The purpose of this study was to examine the distributions of two crosslinks, Pyr and Dpyr, in joint tissues, in order to assess the potential usefulness of urinary Pyr and Dpyr as biochemical markers for the evaluation of arthritis.

\section{Patients and methods}

Articular cartilage, subchondral cancellous bone, and synovial tissue were obtained during operations involving total knee replacement, from 10 patients with OA (aged 58-79 years) and 10 patients with RA (aged 44-73 years), in the Department of Orthopaedic Surgery at the Hamamatsu University School of Medicine. OA patients were diagnosed as having osteoarthritic knee joints on the basis of clinical symptoms, examination, and radiological findings; RA patients were diagnosed according to the American Rheumatism Association 1987 revised criteria for the classification of rheumatoid arthritis. ${ }^{16}$

Synovium was also obtained arthroscopically from 10 non-arthritic (NA) patients (aged 13-76 years) who had suffered trauma to the knee joints. The procedures followed were in accordance with the principles of the 1975 Declaration of Helsinki, as revised in 1983. 
MEASUREMENT OF CROSSLINKS IN TISSUES

The crosslink content of the tissues was measured by a modification of a method described previously. ${ }^{17}$ Briefly, cancellous bone was powdered in liquid nitrogen and demineralised repeatedly with $0.5 \mathrm{~mol} / \mathrm{EDTA}$, $\mathrm{pH} 7 \cdot 4$ (four changes of EDTA solution), cartilage was dissected and homogenised with a Polytron homogeniser, and synovial tissue was dissected and minced. Dissected cartilage and synovium samples were defatted and cleaned by washing with acetone and saline. Samples were hydrolysed in $6 \mathrm{~mol} / \mathrm{l}$ hydrochloric acid $(\mathrm{HCl})(10 \mathrm{mg}$ wet weight/ $\mathrm{ml})$ at $110^{\circ} \mathrm{C}$ for 20 hours in a sealed glass tube. The hydrolysate $(0.125 \mathrm{ml})$ was mixed with $15 \mathrm{ml}$ of distilled water and applied to an SP-Sephadex C25 column $(0.8 \times 1.0 \mathrm{~cm})$. After washing with $20 \mathrm{ml}$ of $0.15 \mathrm{~mol} / \mathrm{HCl}$ Pyr and Dpyr were eluted with $5 \mathrm{ml}$ of 1.0 $\mathrm{mol} / \mathrm{HCl}$. After evaporation, the residue was dissolved in $200 \mu$ l of a $1 \%$ heptafluorobutyric acid (HFBA) solution. The solutions were stored at $-30^{\circ} \mathrm{C}$ until required for analysis by high performance liquid chromatography (HPLC). The HPLC system consisted of a pump (Model CCPM, TOSOH, Tokyo, Japan), a spectrofluorimeter (Model FS-8010, TOSOH), and a system controller (Model SC8010 , TOSOH $)$. A column $(8 \mathrm{~mm} \times 10 \mathrm{~cm})$ prepacked with Radial-Pak C18, of $10 \mu \mathrm{m}$ particle size, type $8 \mathrm{C} 1810 \mathrm{u}$ (Waters Associates Inc, Milford, MA, USA) was used. A mobile phase of acetonitrile and $40 \mathrm{mmol} / \mathrm{HFBA}$ $(27: 73, v / v)$ was used, with a flow rate of 1.0 $\mathrm{ml} / \mathrm{min}$. The volume of each sample injected was $160 \mu \mathrm{l}$. The fluorescence at $390 \mathrm{~nm}$ was measured on excitation at $297 \mathrm{~nm}$. The lower limit of detection of Pyr (signal to noise ratio $=4$ ) was $1 \cdot 2 \mathrm{pmol}$ per one injection under our experimental conditions.

The hydroxyproline content of the hydrolysed tissue samples was measured on a Model 835-50 automated amino acid analyser system (Hitachi, Tokyo, Japan). ${ }^{18}$ The collagen content was calculated assuming $285 \mathrm{~mol}$ of hydroxyproline/mol of collagen, and the amounts of crosslinks contained in the samples were expressed per mol of collagen.

\section{STATISTICAL ANALYSIS}

The statistical significance of differences was determined with non-parametric statistics using Mann-Whitney $U$ tests between two groups and by Kruskall-Wallis among three groups. The analysis was performed with StatView II on a Macintosh computer. Values of $p$ less than 0.05 were considered significant.

\section{Results}

Figure 1 shows typical chromatograms of the joint tissues from patients with OA or RA, and of synovium from non-arthritic subjects. The chromatogram profile of each tissue was
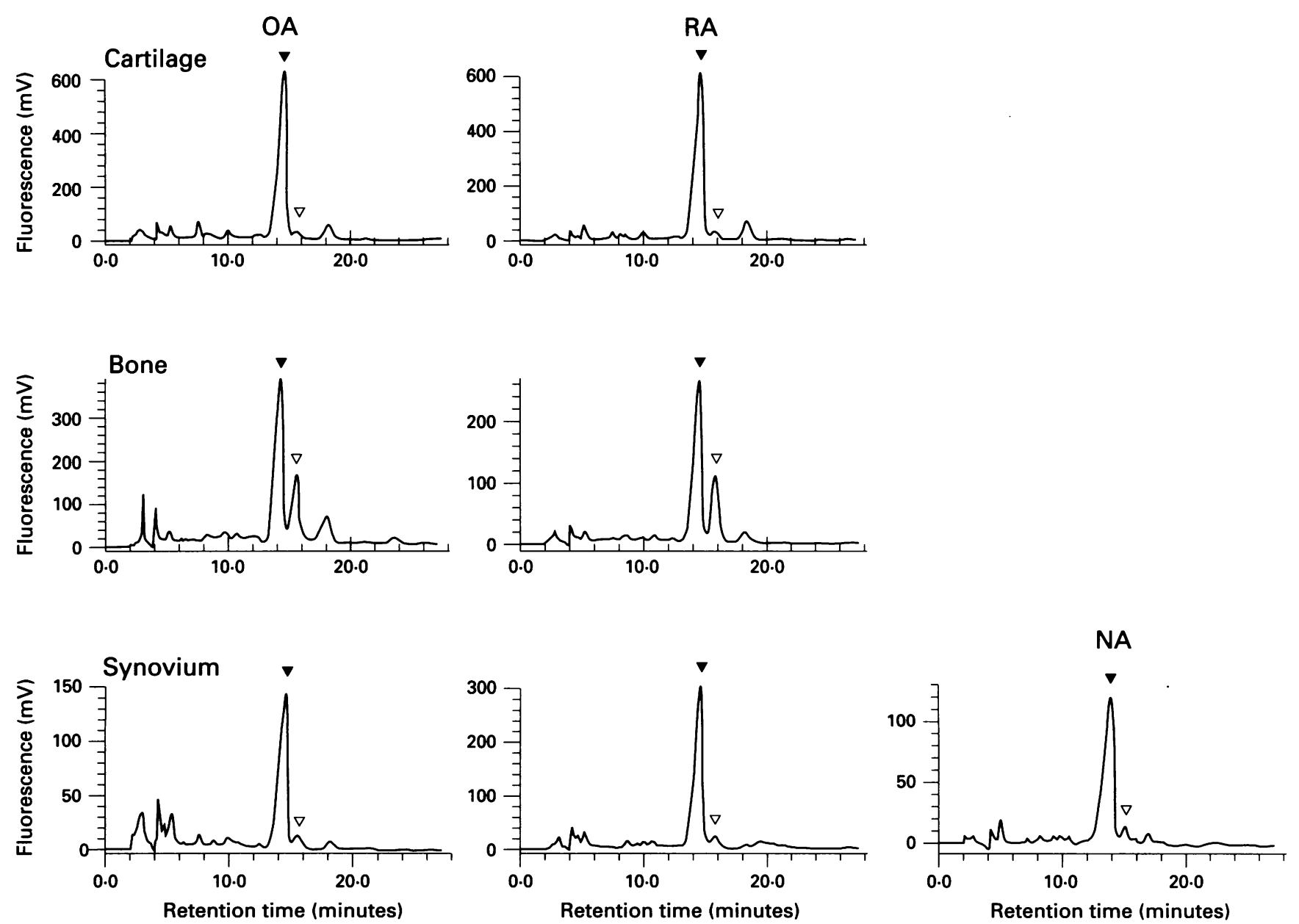

Figure 1 Typical chromatograms of joint tissues (cartilage, bone, and synovium) in osteoarthritis (OA) and rheumatoid arthritis (RA), and synovium from non-arthritic joints (NA). $\nabla=$ Pyridinoline; $\nabla=$ deoxypyridinoline. 
Concentrations of pyridinoline (Pyr) and deoxypyridinoline (Dpyr) and their ratio (Pyr:Dpyr) in joint tissues of patients with osteoarthritis $(O A)$ or rheumatoid arthritis (RA)

\begin{tabular}{llclr}
\hline & & $\begin{array}{l}\text { Pyr } \\
(\text { mmolmol collagen })\end{array}$ & $\begin{array}{l}\text { Dpyr } \\
(\text { mmolmol collagen })\end{array}$ & Pyr:Dpyr \\
\hline Cartilage & OA & $988(86)$ & $26 \cdot 6(2 \cdot 6) \dagger$ & $41 \cdot 2(6 \cdot 5)$ \\
Bone & RA & $1047(121)$ & $19 \cdot 0(2 \cdot 5)$ & $67 \cdot 7(12 \cdot 5)$ \\
& OA & $139(16)$ & $46 \cdot 9(4 \cdot 7)^{\star \star}$ & $3 \cdot 0(0 \cdot 2)$ \\
Synovium & RA & $157(16)$ & $46 \cdot 8(5 \cdot 6)^{\star \star}$ & $3 \cdot 5(0 \cdot 2)$ \\
& OA & $466(35)$ & $25 \cdot 6(4 \cdot 2)$ & $25 \cdot 6(6 \cdot 2)$ \\
& RA & $485(26)$ & $19 \cdot 4(2 \cdot 6)$ & $30 \cdot 4(5 \cdot 0)$ \\
\hline
\end{tabular}

Values are mean (SE). Pyr:Dpyr was calculated for each sample; the means (SE) of these are presented in the last column.

tSignificant difference $(\mathrm{p}<0.05)$ compared with value for RA (Mann-Whitney $U$ test). *Significant differences $(\mathrm{p}<0 \cdot 05)$ among cartilage, bone, and synovium from both OA and RA (Kruskall-Wallis). ${ }^{\star}$ Significant difference $(p<0.01)$ compared with values in cartilage and synovium (Kruskall-Wallis)

similar in OA and RA, and the chromatogram profile of synovial tissue was similar among OA, RA, and NA tissues.

The table shows the concentrations of crosslinks and the Pyr:Dpyr ratio in cartilage, bone, and synovium from OA and RA joints. For each of the tissues there was no significant difference between $O A$ and $R A$ in the concentrations of crosslinks and the Pyr:Dpyr ratio, except that the concentration of Dpyr in OA cartilage was significantly greater than that in RA cartilage $(p<0.05)$. In both OA and $\mathrm{RA}$, the concentrations of Pyr and the Pyr:Dpyr ratio were significantly different when the three joint tissues were compared $(p<0.05)$. The Pyr:Dpyr ratio in bone was approximately 3, that in synovial tissues was about 25 , and that in cartilage was approximately 50. The concentrations of Dpyr in bone were significantly greater than those in cartilage and synovium $(p<0 \cdot 01)$, but there was no significant difference in Dpyr content between cartilage and synovium.

Figure 2 shows the concentrations of $\mathrm{Pyr}$ and Dpyr, and their ratio, in synovium from OA, RA, and non-arthritic (NA) subjects. The Pyr:Dpyr ratio tended to be greater in RA than in samples from non-arthritic subjects, but there was no significant difference in the content of Pyr and Dpyr, and the Pyr:Dpyr ratio among the $\mathrm{OA}, \mathrm{RA}$, and NA groups.

\section{Discussion}

Although Pyr and Dpyr are both mature crosslinks of collagen molecules in the tissues, their distributions and concentrations in various tissues are different. Pyr is most
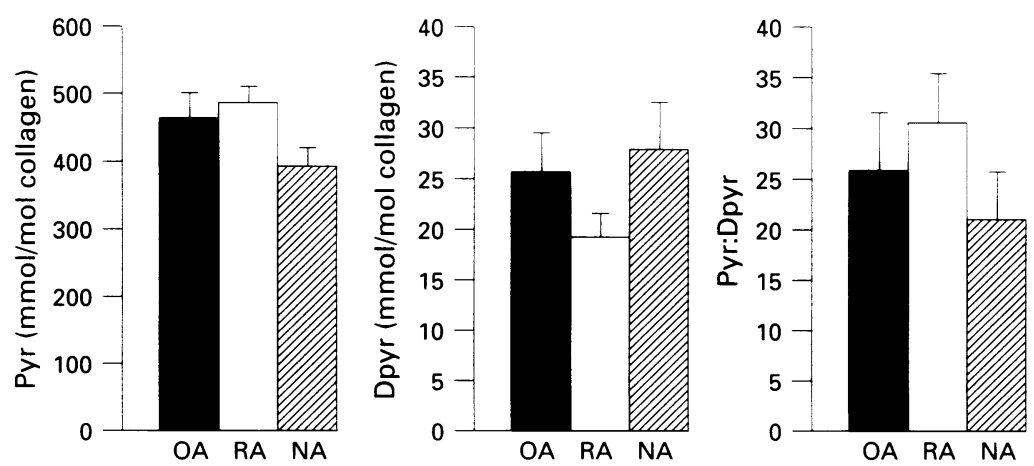

Figure 2 Concentrations of pyridinoline (Pyr) and deoxypyridinoline (Dpyr) and their ratio (Pyr:Dpyr) in synovium from patients with osteoarthritis $(O A)$ or rheumatoid arthritis $(R A)$, and non-arthritic controls $(N A)$. Bar indicates $S E$. abundant in bone and cartilage, though it is widely distributed in most tissues except the skin. Urinary Pyr is generally considered to have its origin in bone, as the turnover of bone is believed to be much greater than that of the other tissues, ${ }^{7}$ and because the distribution of Pyr among the tissues favours cartilage and bone, urinary Pyr crosslinks have been proposed as markers of arthritis. It has recently been suggested ${ }^{19}$ that these crosslinks in urine might originate primarily from periarticular lesions of bone in OA, and as osteopenia is known also to be a major pathology in RA, the increased urinary concentrations of these crosslinks in RA may also originate partly from periarticular lesions of bone, in addition to bone itself.

In contrast to the wide distribution of Pyr, that of Dpyr has been considered to be more restricted-primarily to bone and dentin - and it was therefore proposed that Dpyr could be a more specific marker of bone metabolism than Pyr. However, the distribution of Dpyr in ligament and aorta has subsequently been reported, ${ }^{20} 21$ and our measurements of the concentrations of crosslinks in joint tissues in the present study have shown that Dpyr was also located in cartilage and synovium. Although no data have been published previously concerning the synovial content of Pyr and Dpyr, in this study we have found a significant amount of both in synovium. As synovial tissues undergo relatively rapid turnover in arthritis, especially in RA, the urinary excretion of Pyr and Dpyr may correlate with the turnover and inflammation of synovium.

We reported previously that the joint disorder did not affect the content of Pyr in cartilage. ${ }^{17}$ In the present study, the type of arthritis did not affect the content of pyridinium crosslinks in the joint tissues, while in synovium, the content of pyridinium crosslinks did not change in arthritic compared with non-arthritic tissues. Changes in urinary excretion of pyridium crosslinks therefore reflect the turnover of joint tissues affected by arthritis, but not change in the content of crosslinks in arthritic tissues.

Although Dpyr was found in both cartilage and synovium, its proportion in relation to Pyr is much less in all other tissues (including cartilage and synovium) than in bone. Several observers have measured urinary pyridinium crosslinks in arthritis: most previous studies examining $\mathrm{OA}$ or $\mathrm{RA}$ reported a tissue Pyr:Dpyr ratio of 4-5, though the ratio excreted in the urine ranged from $3 \cdot 3$ to $11 \cdot 4$. Although no tendency of change in the ratio of Pyr to Dpyr in arthritis has been established in previous published data, one study showed that the ratio was greater in RA than in control patients, ${ }^{10}$ and it has also been reported that the ratio was greater in active $R A$ than in inactive RA. ${ }^{11}$ As the results of our study have shown the ratio of Pyr to Dpyr to be much greater in cartilage (50:1) and synovium (25:1) than in bone (3:1), it is likely that part of the urinary excretion of Pyr and Dpyr may be contributed from tissues other than bone, 
namely cartilage and synovium. The urinary concentrations of Pyr and Dpyr and the Pyr:Dpyr ratio are dependent on two factors: the relative abundance of the crosslinks in the tissues and the rate of turnover of the tissues. As cartilage and synovium have a much greater Pyr:Dpyr ratio than has bone, increased turnover of cartilage or synovium, or both, would contribute little to urinary excretion of Dpyr, but would significantly increase urinary excretion of Pyr. If the turnover rate of cartilage and synovium is the same, urinary excretion of Pyr would receive a greater contribution from cartilage than from synovium, because of the greater Pyr content and greater Pyr:Dpyr ratio of cartilage. However, if the rate of turnover of synovium is greater than that of cartilage, synovium would contribute more to the urinary excretion of Pyr than would cartilage.

In conclusion, cartilage and synovium contribute to the urinary excretion of pyridinium crosslinks, and the crosslinks may thus be useful as indices of arthritis. Moreover, the significant content of pyridinoline found in synovium suggests that the urinary excretion of pyridinoline may also reflect synovial turnover and synovial inflammation.

We thank Dr Kiyohito Saito for help in collecting the tissue samples from the patients with osteoarthritis. Part of this work
was supported by the grant from the Japan Orthopaedics and Traumatology Foundation, Inc (JOTF), No 0043.

1 Fujimoto D, Akiba $\mathrm{K}$, Nakamura $\mathrm{N}$. Isolation and characterization of a fluorescent material in bovine achilles tendon collagen. Biochem Biophys Res Commun 1977; 76: 1124-9.

2 Fujimoto D, Moriguchi T. Pyridinoline, a non-reducible crosslink of collagen. 7 Biochem 1978; 83: 863-7.

3 Ogawa T, Ono T, Tsuda M, Kawanishi Y. A novel fluor in insoluble collagen: A crosslinking moiety in collagen insoluble collagen: A crosslinking moiety in collagen
molecule. Biochem Biophys Res Commun 1982; 107: molecule.

4 Eyre D R, Koob T J, Van Ness K P. Quantitation of hydroxypyridinium crosslinks in collagen by highperformance liquid chromatography. Anal Biochem 1984; 137: $380-8$.

5 Farquharson C, Duncan A, Robins S P. The effect of copper deficiency on the pyridinium crosslinks of mature collagen in the rat skeleton and cardiovascular system. Proc Soc Exp Biol Med 1989; 192: 166-71.
6 Orth M W, Martinez D A, Cook M E, Vailas A C. Nonreducible crosslinks formation in tibial dyschondroplastic growth plate cartilage from broiler chicks fed homocysteine.

7 Editorial. Pyridinium crosslinks as markers of bone resorption. Lancet 1992; 340: 278-9.

8 Robins S P. An enzyme-linked immunoassay for the collagen cross-link pyridinoline. Biochem $\mathcal{f} 1982 ; 207$ 617-20.

9 Fujimoto D, Suzuki M, Uchiyama A, Miyamoto S, Inoue $T$. Analysis of pyridinoline, a cross-linking compound of collage

10 Black D, Marabani M, Sturrock R D, Robins S P. Urinary excretion of the hydroxypyridinium crosslinks of collagen in patients with rheumatoid arthritis. Ann Rheum Dis in patients with

11 Seibel M J, Duncan A, Robins S P. Urinary hydroxypyridinium crosslinks provide indices of cartilage and bone involvement in arthritic diseases. $\mathcal{F}$ Rheumatol 1989 16: $964-70$.

12 Thompson $P$ W, Spector T D, James I T, Henderson E, Hart D J. Urinary collagen crosslinks reflect the radiographic severity of knee osteoarthritis. $B r f \mathcal{f}$ Rheumatol 1992; 31: 759-61.

13 Spector T D, James I T, Hall G $M$, Thompson P W, Perrett D, Hart D J. Increased levels of urinary collagen crosslinks in females with rheumatoid arthritis. Clin Rheumatol 1993; 12: 240-4.

14 Gough A K S, Peel N F A, Eastell R, Holder R L Lilley J, Emery P. Excretion of pyridinium crosslinks correlates with disease activity and appendicular bone loss in early rheumatoid arthritis. Ann Rheum Dis 1994; 53: $14-7$.

15 Kollerup G, Hansen M, Horslev-Petersen K. Urinary hydroxypyridinium cross-links of collagen in rheumatoid arthritis. Relation to disease activity and effects of methylprednisolone. Br $\mathcal{F}$ Rheumatol 1994; 33: 816-20.

16 Arnett F C, Edworthy S M, Bloch D A, et al. The American Rheumatism Association 1987 revised criteria for the classification of rheumatoid arthritis. Arthritis Rheum 1988; 31: 315-24

17 Takahashi M, Kushida K, Ohishi T, et al. Quantitative analysis of crosslinks pyridinoline and pentosidine in articular cartilage of patients with bone and joint disorders. Arthritis Rheum 1994; 37: 724-8.

18 Uchiyama A, Ohishi T, Takahashi M, et al. Fluorophores from aging human articular cartilage. $\mathcal{f}$ Biochem 1991; 110: 714-8.

19 MacDanald A G, McHenry P, Robins S P, Reid D M. Relationship of urinary pyridinium crosslinks to disease extent and activity in osteoarthritis. $\operatorname{Br} \mathcal{F}$ Rheumatol 1994; 33: 16-9.

20 Robins S P, Duncan A, Riggs B L. Direct measurement of free hydroxypyridinium crosslinks of collagen in urine as new markers of bone resorption in osteoporosis. In: new markers of bone resorption in osteoporosis. In: proceedings of the third international symposium on proceedings of the third international symposium on osteoporosis. A

21 Hoshino H, Takahashi M, Kushida K, Ohishi T, Kawana $\mathrm{K}$, Inoue $\mathrm{T}$. Quantitation of the crosslinks, pyridinoline, deoxypyridinoline, and pentosidine, in human aorta with dystrophic calcification. Atherosclerosis 1995; 112: 39-46. 